\title{
Parotidectomy using the Harmonic scalpel: ten years of experience at a rural academic health center
}

\author{
Marc A. Polacco ${ }^{1,2^{*}}$, Andrew M. Pintea ${ }^{1}$, Benoit J. Gosselin ${ }^{1}$ and Joseph A. Paydarfar ${ }^{1}$
}

\begin{abstract}
Background: Parotidectomy is one of the most commonly performed procedures by otorhinolaryngologists. Traditionally dissection is performed with a combination of a steel scalpel and bipolar cautery; however, starting in the early 2000s, the Harmonic scalpel has provided an alternative method for dissection and hemostasis. The purpose of this study is to compare operative time, blood loss, complications, and cost between the Harmonic scalpel and steel scalpel plus bipolar cautery for superficial and total parotidectomy.
\end{abstract}

Methods: Retrospective cohort of patients who underwent superficial or total parotidectomy with the Harmonic or cold steel between 2000 and 2015. Across 255 patients, comparison between operative time, blood loss, complications, and cost was performed.

Results: Superficial parotidectomy was performed on 120 patients with the Harmonic and 54 with steel scalpel. Total parotidectomy was performed on 59 patients using the Harmonic and 22 patients with cold steel. For superficial parotidectomy, the Harmonic reduced operative time (216 \pm 42 vs. $234 \pm 54$ min, $p=0.03)$ and decreased blood loss ( $28 \pm 19$ vs. $76 \pm 52 \mathrm{mls}, \mathrm{p}<0.05$ ). With total parotidectomy the Harmonic decreased operative time ( $240 \pm 42$ vs. $288 \pm 78 \mathrm{~min}, p=0.01$ ) and reduced blood loss ( $38 \pm 21 \mathrm{mls}$ vs. $85 \pm 55 \mathrm{mls}, \mathrm{p}<0.05$ ). There were no differences in complication rates between groups. Harmonic use was associated with surgical cost reduction secondary to reduced operative times.

Conclusions: The Harmonic scalpel decreases blood loss and operating time for superficial and total parotidectomy. Shorter operative times may decrease the overall cost of parotidectomy.

Keywords: Parotidectomy, Harmonic, Blood loss, Operative time, Cost

\section{Background}

The incidence of salivary gland neoplasm has been reported to be $1-1.4$ per 100,000 people annually [1]. Relatively rare, salivary gland tumors account for $5 \%$ of all head and neck tumors, the majority of which occur in the parotid gland [2,3]. Patients who are diagnosed with a parotid gland tumor often undergo parotidectomy. While commonly performed, the procedure is technically challenging and time-consuming

\footnotetext{
* Correspondence: Marc.A.Polacco@hitchcock.org

The data within this manuscript were presented at the 9th International Conference on Head and Neck Cancer 2016 Seattle WA.

'Department of Otolaryngology, Dartmouth-Hitchcock Medical Center, Lebanon, NH, USA

${ }^{2}$ Dartmouth-Hitchcock Medical Center, One Medical Center Drive, Lebanon, $\mathrm{NH}$ 03766, USA
}

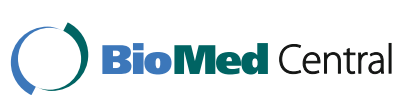

(c) The Author(s). 2017 Open Access This article is distributed under the terms of the Creative Commons Attribution 4.0 International License (http://creativecommons.org/licenses/by/4.0/), which permits unrestricted use, distribution, and reproduction in any medium, provided you give appropriate credit to the original author(s) and the source, provide a link to the Creative Commons license, and indicate if changes were made. The Creative Commons Public Domain Dedication waiver (http://creativecommons.org/publicdomain/zero/1.0/) applies to the data made available in this article, unless otherwise stated. region with high vascularity.

The Harmonic scalpel (HS) (Ethicon, Somerville, NJ), an instrument which utilizes ultrasonic vibrations to induce cutting and immediate coagulation of tissue, was introduced in the early 1990s. A low power setting allows for greater hemostasis and slower cutting, while a high power setting offers less hemostasis but faster cutting ability. Since its introduction, the HS has been shown to reduce operative time and intra-operative blood loss across a range of otolaryngologic procedures including thyroidectomy, parotidectomy, glossectomy, and neck dissection [4-7].

The HS reduces bleeding and prevents thermal injury to surrounding tissues greater than 2-3 $\mathrm{mm}$ 
distance, making it an ideal instrument for procedures requiring fine dissection $[8,9]$. Prior studies have shown that the HS is useful for reducing blood loss and operative time in superficial and total parotidectomy procedures when compared to using a steel scalpel and bipolar cautery; however, most have contained relatively small cohorts over brief study periods [10-12]. To our knowledge, this is the largest study comparing parotidectomy outcomes between the HS and steel scalpels plus bipolar cautery (SB), and the first to report superficial and total parotidectomy outcomes separately (Table 1). Moreover, this study reports the effect HS use has on the overall cost of performing a parotidectomy.

\section{Methods}

The medical records of all patients who underwent superficial or total parotidectomy at DartmouthHitchcock Medical Center from 2000-2015 were retrospectively reviewed after gaining approval from the institutional review board. A total of 424 cases were identified. Cases were excluded if the patient had history of prior parotid surgery, radiation, a bleeding disorder, prior facial nerve disorder, was lost in follow up, or if they underwent a combination of procedures such as parotidectomy with neck dissection. This resulted in exclusion of 148 cases. An additional 21 cases were excluded as they were performed by two surgeons who did not routinely perform parotidectomies, defined as less than five parotidectomies per year (Fig. 1).

All included cases were performed by two surgeons (Table 2). For both surgeons, cases prior to 2006 were performed with a combination of steel scalpels and bipolar cautery, while most cases after 2006 were performed with the Harmonic scalpel. A resident surgeon was present in $81 \%$ of cases.

In addition to categorizing cases according to superficial and total parotidectomy with or without use of the HS, cases meeting inclusion criteria were assessed for patient age, sex, operative time, blood loss, postoperative drain output, length of follow up, and complications. Complications assessed included hematoma, seroma, Frey's syndrome, facial nerve weakness, auricular numbness, keloid, and first bite syndrome. The cost of each procedure was calculated using the reported operating room cost per minute for superficial and total parotidectomy multiplied by total minutes to procedure completion. If the HS was opened, the cost of the instrument was added to the cost of the surgical case. The percentage of cost reduction was calculated by taking the ratio of cost of parotidectomy with HS to that of SB, averaged across all procedures. Statistical analyses were conducted using unpaired t-tests for contiguous data and Fisher's exact test for categorical data (Microsoft Excel 2013, Redmond, WA).

Table 1 Literature comparing parotidectomy outcomes

\begin{tabular}{|c|c|c|c|c|c|}
\hline Surgery & Instrument & No. & OR Time (min) & Blood Loss (ml) & Drain Output (ml) \\
\hline \multicolumn{6}{|l|}{ Superficial parotid } \\
\hline \multirow[t]{2}{*}{ Muhanna et al. 2014 [12] } & SB & 32 & $163.12 \pm 21.8$ & $N R^{a}$ & $73.5 \pm 38.2$ \\
\hline & HS & 26 & $137.3 \pm 18.6$ & $N R^{a}$ & $68 \pm 22.3$ \\
\hline \multirow[t]{2}{*}{ Blankenship et al. 2004 [11] } & SB & 21 & $195.5 \pm 37.5$ & $60.0 \pm 37.1$ & $48.7 \pm 33.8$ \\
\hline & $\mathrm{HS}$ & 19 & $167.5 \pm 42.6$ & $37.5 \pm 25.8$ & $48.0 \pm 22.7$ \\
\hline \multirow[t]{2}{*}{ Jackson et al. 2005 [10] } & SB & 37 & $N R^{a}$ & $68 \pm 12$ & $N R^{a}$ \\
\hline & HS & 35 & $N R^{a}$ & $38 \pm 4.23$ & $N R^{a}$ \\
\hline \multirow[t]{2}{*}{ Polacco et al. } & SB & 54 & $234 \pm 54$ & $76 \pm 52$ & $43 \pm 36$ \\
\hline & $\mathrm{HS}$ & 120 & $216 \pm 42$ & $28 \pm 19$ & $24 \pm 15$ \\
\hline \multicolumn{6}{|l|}{ Total parotid } \\
\hline \multirow[t]{2}{*}{ Jackson et al. 2005 [10] } & SB & 4 & $N R^{a}$ & $N R^{a}$ & $N R^{a}$ \\
\hline & $\mathrm{HS}$ & 9 & $N R^{a}$ & $N R^{a}$ & $N R^{a}$ \\
\hline \multirow[t]{2}{*}{ Polacco et al. } & SB & 22 & $288 \pm 42$ & $85 \pm 55$ & $33 \pm 20$ \\
\hline & HS & 59 & $240 \pm 78$ & $38 \pm 21$ & $35 \pm 30$ \\
\hline \multicolumn{6}{|l|}{ Superficial and Total parotid } \\
\hline \multirow[t]{2}{*}{ Deganello et al. 2014 [5] } & SB & 63 & $151.6 \pm 54.1$ & $N R^{a}$ & $78 \pm 81$ \\
\hline & HS & 67 & $146.9 \pm 39.9$ & $N R^{a}$ & $69 \pm 52$ \\
\hline \multirow[t]{2}{*}{ Jackson et al. 2005 [10] } & SB & 41 & $200.5 \pm 41.43$ & $66.0 \pm 10.8$ & $N R^{a}$ \\
\hline & $\mathrm{HS}$ & 44 & $183.88 \pm 58.17$ & $38.0 \pm 3.6$ & $N R^{a}$ \\
\hline
\end{tabular}




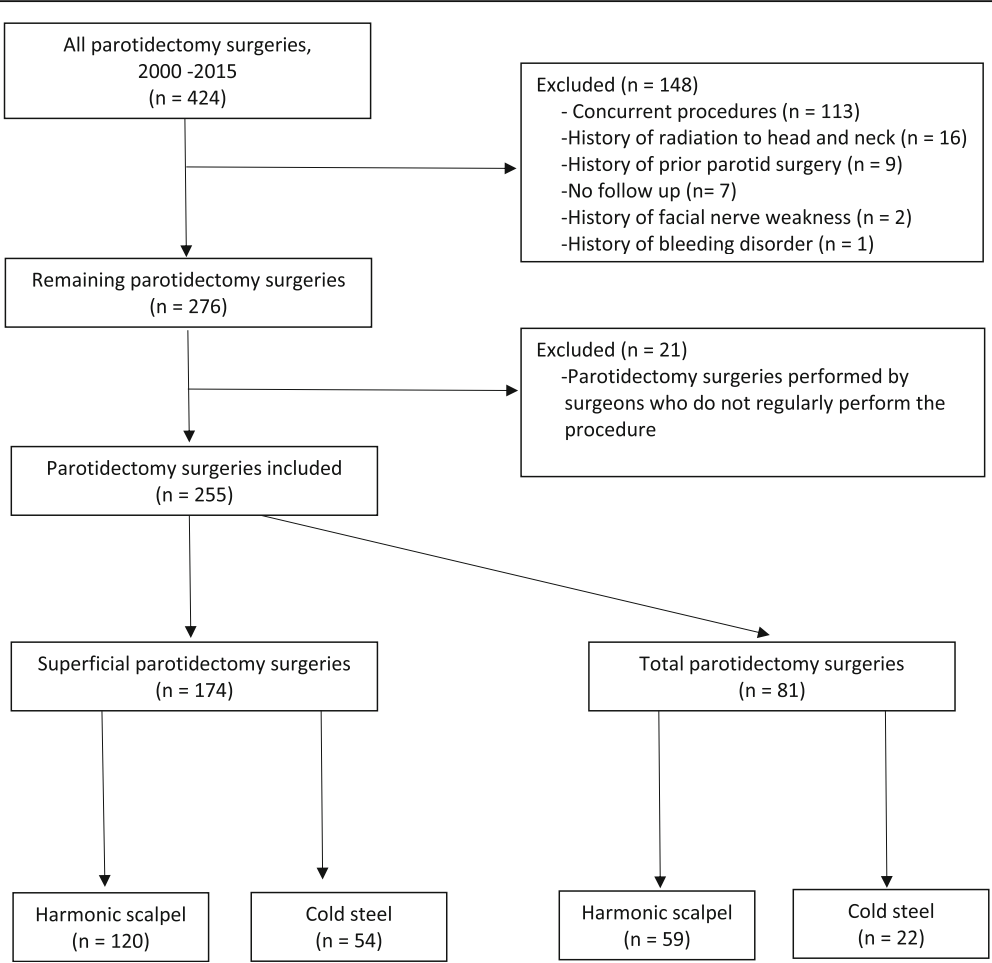

Fig. 1 Inclusion criteria flow chart

\section{Results}

\section{Superficial parotidectomy}

A total of 174 patients underwent superficial parotidectomy, 120 with the HS and 54 with SB. There was no significant difference for patient age, sex, and mean follow up duration between groups. Use of the HS compared with SB resulted in shorter duration of surgery ( $216 \pm 42$ vs. $234 \pm 54 \mathrm{~min}, p=0.03$ ) and less blood loss $(28 \pm 19 \mathrm{mls}$ vs. $76 \pm 52 \mathrm{mls}, \mathrm{p}<0.05)$, but no significant difference in post-operative drain output ( $24 \pm 15 \mathrm{mls}$ vs. $43 \pm 36 \mathrm{mls}, p=0.09$ ) or complications (Table 3). Taking the cost of the HS into account, there was a 5.6\% average reduction in cost for superficial parotidectomy procedures when the HS was used.

\section{Total parotidectomy}

In the total parotidectomy group, there were a total of 81 patients who met inclusion criteria, 59 of whom

Table 2 Cases per surgeon

\begin{tabular}{lll}
\hline Parotidectomy & Surgeon 1 & Surgeon 2 \\
\hline Superficial (SB) $^{\mathrm{a}}$ & 21 & 33 \\
${\text { Superficial }(\mathrm{HS})^{\mathrm{a}}}^{\mathrm{T}}$ & 64 & 56 \\
${\text { Total }(\mathrm{SB})^{\mathrm{a}}}^{\mathrm{T}}$ & 13 & 9 \\
${\text { Total }(\mathrm{HS})^{\mathrm{a}}}_{\text {Sum Total Cases }}$ & 28 & 31 \\
& 126 & 129
\end{tabular}

${ }^{a} S B$ steel scalpel plus bipolar cautery, HS Harmonic scalpel underwent surgery using the HS and 22 with SB. There was no significant difference in regard to patient age, sex, and mean follow up duration between groups. With total parotidectomy, use of the HS compared with SB resulted in shorter duration of surgery ( $240 \pm 42$ vs. $288 \pm 78 \mathrm{~min}$, $p=0.01)$ and less blood loss $(38 \pm 21 \mathrm{mls}$ vs. $85 \pm 55 \mathrm{mls}$, $p<0.05$ ), but no significant difference in post-operative drain output $(35 \pm 30 \mathrm{mls}$ vs. $33 \pm 20 \mathrm{mls}, p=0.78)$ or complications. HS use resulted in a $15 \%$ average cost reduction of total parotidectomy.

\section{Discussion}

The HS utilizes ultrasonic vibration to denature proteins, forming a coagulum for hemostasis while also limiting thermal injury to surrounding tissue. Since the introduction of the HS, it has been shown to be effective in decreasing operative blood loss across a variety of procedures, from total colectomy to hepatectomy [13, 14]. In the otolaryngology literature, the HS has been shown to decrease blood loss and operative times for thyroidectomies, parotidectomies, and neck dissections $[10,15,16]$.

This study is the largest to date comparing the Harmonic Scalpel to cold steel in parotidectomy. Our results corroborate prior parotidectomy studies on the HS, showing both a reduction in blood loss and decrease in operating room time when compared to SB (see Table 1). The benefit of using the HS in total parotidectomy procedures is even more compelling as the differences in blood 
Table 3 Patient characteristics and outcomes

\begin{tabular}{|c|c|c|c|c|c|c|}
\hline \multirow[b]{2}{*}{ Variables } & \multicolumn{3}{|c|}{ Superficial $(n=174)$} & \multicolumn{3}{|c|}{ Total $(n=81)$} \\
\hline & $\mathrm{HS}(n=120)$ & $\mathrm{SB}(n=54)$ & $P$ value & HS $(n=59)$ & $\mathrm{SB}(n=22)$ & $P$ Value \\
\hline Mean age (years) & $59 \pm 14$ & $56 \pm 15$ & 0.19 & $56 \pm 15$ & $55 \pm 14$ & 0.75 \\
\hline \multicolumn{7}{|l|}{ Sex } \\
\hline Male & $56(47 \%)$ & $24(43 \%)$ & 0.87 & $31(53 \%)$ & $10(45 \%)$ & 0.62 \\
\hline Female & $64(53 \%)$ & $30(56 \%)$ & & $28(47 \%)$ & $12(55 \%)$ & \\
\hline Blood Loss (ml) & $28 \pm 19$ & $76 \pm 52$ & $<0.05$ & $38 \pm 21$ & $85 \pm 55$ & $<.05$ \\
\hline Drain Output (ml) & $24 \pm 15$ & $43 \pm 36$ & 0.09 & $35 \pm 30$ & $33 \pm 20$ & 0.78 \\
\hline OR Time (min) & $216 \pm 42$ & $234 \pm 54$ & 0.03 & $240 \pm 42$ & $288 \pm 78$ & 0.01 \\
\hline Length of Follow Up (mo) & $7 \pm 12$ & $7 \pm 7$ & 0.13 & $9 \pm 6$ & $13 \pm 12$ & 0.17 \\
\hline \multicolumn{7}{|l|}{ Complications } \\
\hline Auricular Numbness & $7(5 \%)$ & $2(4 \%)$ & 0.72 & $5(8 \%)$ & $3(14 \%)$ & 0.68 \\
\hline Transient facial paresis & $1(0.8 \%)$ & $2(4 \%)$ & 0.23 & $1(1.6 \%)$ & $1(4.5 \%)$ & 1 \\
\hline Permanent facial paresis & 0 & 0 & 1 & $1(1.6 \%)$ & 0 & 1 \\
\hline Facial paralysis & 0 & 0 & 1 & 0 & 0 & 1 \\
\hline Hematoma & 0 & 0 & 1 & 0 & 0 & 1 \\
\hline Seroma & $1(0.8 \%)$ & 0 & 1 & 0 & 0 & 1 \\
\hline Keloid & $1(0.8 \%)$ & 0 & 1 & 0 & 0 & 1 \\
\hline Frey's syndrome & 0 & 0 & 1 & 0 & $1(4.5 \%)$ & 1 \\
\hline First Bite & $1(0.8 \%)$ & 0 & 1 & 0 & 0 & 1 \\
\hline Average Cost (including cost of Harmonic Scalpel) & $\$ 23,190$ & $\$ 24,570$ & & $\$ 25,710$ & $\$ 30,240$ & \\
\hline
\end{tabular}

loss and operative time between groups was greater. While the difference in blood loss between groups in this study was significant statistically, it is unlikely that the volume of blood saved using the HS is clinically significant.

For both the superficial and total parotidectomy groups, there was a significant difference in operative time between the use of the HS and SB dissection. For the superficial group, the amount of time saved using the HS equated to $18 \mathrm{~min}$, while this difference increased to $48 \mathrm{~min}$ in the total parotidectomy group. At our institution the amount of operating room time saved, even in the superficial parotidectomy group, translates into a cost reduction greater than the cost of the HS, resulting in a $\$ 1381$ (5.6\%) and a $\$ 4530$ (15\%) decrease in cost of performing superficial and total parotidectomy respectively. We expect the percentage of cost reduction to be relatively consistent across institutions, whereas the monetary value could be highly variable depending on operating room utilization cost per institution. These data are compelling as healthcare costs continue to soar in the United States and cost reduction efforts become increasingly important. In $2014,17.1 \%$ of the gross domestic product was allocated for health-care, and the Congressional Budget Office estimates this figure to increase to $25 \%$ by 2025 should the rate of increasing expenditures remain constant [17]. Being at the forefront of health-care expenditure, physicians have an obligation to create efforts to control cost in order to continue to provide accessible quality health-care [18].

Moreover, with a decrease in operative time there is also a realized reduction in opportunity cost. Opportunity cost is traditionally defined as the value of a rejected opportunity or alternative [19]. By reducing the overall operative time allocated to performing a parotidectomy, particularly total resections, time resources may be redistributed to endeavors such as additional cases, research, or education. Additionally, this reduction in opportunity cost could translate to increased patient access to providers.

A weakness of this study is that there is no method to determine the degree of resident involvement in the $81 \%$ of cases in which there was a resident present. While it could be presumed that junior residents would operate at a slower rate than senior residents, the amount of actual operating time for each resident is likely highly variable as senior residents are granted more autonomy while there is traditionally more attending physician involvement when a junior resident is operating. While one of two attending physicians were present for all cases reported, it is possible that surgeons operating without a resident may not experience a significant difference in blood loss, operating time, or cost. 


\section{Conclusion}

Use of the HS for superficial and total parotidectomy is associated with a significantly shorter duration of surgery and less blood loss when compared to use of SB. Shorter operative times were great enough to generate cost savings to offset the cost of the HS and decrease the overall cost of parotidectomy.

\section{Acknowledgements}

None.

\section{Funding}

This research did not receive any specific grant from funding agencies in the public, commercial, or not-for-profit sectors.

\section{Availability of data and materials}

The datasets used and/or analyzed during the current study are available from the corresponding author on reasonable request.

\section{Author contributions}

MP, JP, Study concept and design. MP, AP, BG, JP, Acquisition, analysis, or data interpretation. MP, AP, BG, JP, Drafting of manuscript. MP, AP, BG, JP, Critical revision for important intellectual content. MP, AP, Statistical analysis. BG, JP, Study supervision. All authors read and approved the final manuscript.

\section{Competing interests}

The authors declare that they have no competing interests.

\section{Consent for publication}

Not applicable.

\section{Ethics approval and consent to participate}

As there are no patient identifiers, this study was waived by the institutional review board of Dartmouth-Hitchcock Medical Center (STUDY00029066).

\section{Publisher's Note}

Springer Nature remains neutral with regard to jurisdictional claims in published maps and institutional affiliations.

Received: 31 January 2017 Accepted: 5 May 2017

Published online: 11 May 2017

\section{References}

1. Kimberly $H$, Lin $H$, Ann D, Chu P, Yen Y. An overview of the rare parotid gland cancer. Head Neck Oncol. 2011;3(9):40.

2. Laurie S, Licitra L. Systemic therapy in the palliative management of advanced salivary gland cancers. J Clin Oncol. 2006:24(17):2673-8.

3. O'Brien C, Soong S, Herrera G, Urist M, Maddox W. Malignant salivary tumors-analysis of prognostic factors and survival. Head Neck Surg. 1986;9(2):82-92.

4. Koh Y, Park J, Lee S, Choi E. The harmonic scalpel technique without supplementary ligation in total thyroidectomy with central neck dissection: a prospective randomized study. Ann Surg. 2008;247(6):945-9.

5. Deganello A, Meccariello G, Busoni M, Parrinello G, Bertolai R, Gallo O. Dissection with harmonic scalpel versus cold instruments in parotid surgery B-ENT. 2014:10(3):175-8.

6. Pons Y, Gauthier J, Clement P, Conessa C. Ultrasonic partial glossectomy Head Neck Oncol. 2009;6(1):21.

7. Dean A, Alamillos F, Centella I, Garcia-Alvarez S. Neck dissection with the Harmonic scalpel in patients with squamous cell carcinoma of the oral cavity. J Craniomaxillofac Surg. 2014;42(1):84-7.

8. Koch C, Friedrich T, Metternich F, Tannapfel A, Reimann H, Eichfeld U. Determination of temperature elevation in tissue during the application of the harmonic scalpel. Ultrasound Med Biol. 2003;29(2):301-9.

9. Tirelli G, Camilot D, Bonini P, Del Piero G, Biasotto M, Quatela E. Harmonic scalpel and electrothermal bipolar vessel sealing system in head and neck surgery: a prospective study on tissue heating and histological damage on nerves. Ann Otol Rhinol Laryngol. 2015;124(11):852-8.
10. Jackson L, Gourin C, et al. Use of the harmonic scalpel in Superficial and total parotidectomy for benign and malignant disease. Laryngoscope. 2005;115:1070-3.

11. Blankenship D, Gourin C, Porubsky E, et al. Harmonic scalpel versus cold knife dissection in superficial parotidectomy. Otolaryngol Head Neck Surg. 2004;131(4):397-400

12. Muhanna N, Peleg U, Schwartz Y, Shaul H, Perez R, Sichel J. Harmonic scalpel assisted superficial parotidectomy. Ann Otol Rhinol Laryngol. 2014; 123(9):636-40.

13. Bodzin A, Leiby B, Ramirez C, Frank A, Doria C. Liver resection using cavitron ultrasonic surgical aspirator (CUSA) versus harmonic scalpel: a retrospective cohort study. Int J Surg. 2014;12(5):500-3.

14. Rimonda R, Arezzo A, Garrone C, Allaix M, Giraudo G, Morino M. Electrothermal bipolar vessel sealing system vs. harmonic scalpel in colorectal laparoscopic surgery: a prospective, randomized study. Dis Colon Rectum. 2009;52(4):657-61.

15. Da Silva F, Limoeiro A, Del Bianco J, et al. Impact of the use of vessel sealing or harmonic scalpel on intra-hospital outcomes and the cost of thyroidectomy procedures. Einstein. 2012;10(3):354-9.

16. Shin Y, Koh Y, Kim S, Choi E. The efficacy of the Harmonic scalpel in neck dissection: a prospective randomized study. Laryngoscope. 2013;123(4):904-9.

17. The World Bank. Health expenditure, total (\% of GDP). http://data. worldbank.org/indicator/SH.XPD.TOTL.ZS?year_high_desc=true. Accessed 24 May 2016.

18. Bosco J, lorio R, Barber T, Barron C, Caplan A. Ethics of the physician's role in health-care cost control: AOA critical issues. J Bone Joint Surg Am. 2016; 98(14):e58.

19. Spiller S. Opportunity cost consideration. J Consum Res. 2011;38(12):595-610.
Submit your next manuscript to BioMed Central and we will help you at every step:

- We accept pre-submission inquiries

- Our selector tool helps you to find the most relevant journal

- We provide round the clock customer support

- Convenient online submission

- Thorough peer review

- Inclusion in PubMed and all major indexing services

- Maximum visibility for your research

Submit your manuscript at www.biomedcentral.com/submit
Biomed Central 